Epidemiology and Public Health Research Unit, University of Surrey. I am specially indebted to Mr L Bulusu and Dr V S Raleigh for their advice.

1 Anonymous. Coronary heart disease in Indians overseas [Editorial]. Lance 1986;: 1307-8.

2 Marmot MG, Rose G. Epidemiology of hypertension. In: Sleight P, Jones JV eds. Scientific foundations of cardiology. London: Heinemann, 1984

3 Grell GAC. Hypertension in the West Indies. Postgrad Med F 1983;59:616-21. Marmot MG, Adelstein AM, Bulusu L. Immigrant mortality in England and Wales 1970-78: causes of death by country of birth. London: HMSO, 1984 Office of Population Censuses and Surveys, studies on medical and population subjects No 47 .

5 Balarajan R, Bulusu L, Adelstein AM, Shukla V. Patterns of mortality among migrants to England and Wales from the Indian subcontinent. $B M \mathcal{J}$ 1984;289:1185-7.

6 Balarajan R, Bulusu L. Mortality among immigrants in England and Wales, 1979-83. In: Mortality and geographv: a review in the mid-1980s, England and Wales. London: Office of Population Censuses and Surveys, 1990. (Series DS No 9 .

7 McKeigue PM, Marmot MG. Mortality from coronary heart disease in Asian communities in London. B.MF 1988;297:903

8 Derry CW, Bourne DE, Sayed AR, et al Variations in mortality of the coloured, white, and Asian population groups in the RSA, 1978-1982. VI. Ischaemic heart disease. S Afr Med f 1987;72:698-700.

9 Shaper AG, Pocock SJ, Walker M, Phillips AN, Whitehead TP, MacFarlan PW. Risk factors for ischaemic heart disease: the prospective phase of the British regional heart study. I Epidemiol Community Health 1985;39: 197-209.

10 Silman A, Loysen E, de Graaf W, Sramek $M$. High dietary fat intake and cigarette smoking as risk factors for ischaemic heart disease in Bangladeshi male immigrants in east London. F Epidemiol Community Health 1985:39: 301-3.

11 McKeigue PM, Marmot MG, Court YDS, Cottier DE, Rahman S, Riemersm RA. Diabetes, hyperinsulinaemia, and coronary risk factors in Bangladeshi in east London. Br Heart f 1988;60:390-6.

12 Balarajan $R$, Yuen $P$. British smoking and drinking habits: variations by country of birth. Community Med 1986;8:237-9.

13 McKeigue PM. Marmot MG, Adelstein AM, et al. Diet and risk factors for coronary heart disease in Asians in northwest London. Lancet 1985; ii: $1086-90$

14 Miller GJ, Kotecha S, Wilkinson WH, et al. Dietary and other characteristic relevant for coronary heart disease in men of Indian, West Indian and European descent in London. Atherosclerosis 1988;70:63-72.

5 De Giovanni JV, Beevers DG, Jackson SHD, et al. The Birmingham blood pressure school study. Postgrad Med 7 1983;59:627-9.

16 Cruickshank JK, Bannan LT, Beevers M, Jackson SHD, Beevers DG, Osbourne VL. Blood pressure in black, white and Asian factory workers in Birmingham. Postgrad Med f 1983;59:622-6.
17 Keil JE, Weinrich MC, Keil BW, Britt RP, Hollis Y. Hvpertension in a population sample of female Punjabi Indians in Southall. $\mathcal{f}$ Epidemiol Community Health 1980;34:45-7.

18 Seedat YK. Race, environment and blood pressure: the South African experience. F Hypertens 1983;1:7-12.

19 Malhotra SL. Studies in arterial pressure in north and south India with special reference to dietary factors in its causation. $\mathcal{F}$ Assoc Physicians India 1971;19:211-24.

20 Miller GJ, Miller NE. Plasma high density lipoprotein concentration and development of ischaemic heart disease. Lancet 1975; ; 16-9.

21 Gordon T, Castelli WP, Hjortland MC, Kannel WB, Dawber TR. High density lipoprotein as a protective factor against coronary heart disease. The Framingham study. Am F Med 1977;62:707-14.

22 Pocock SJ, Shaper AG, Phillips AN, Walker M, Whitehead TP. High density lipoprotein cholesterol is not a major risk factor for ischaemic heart disease in British men. BMf 1986;292:515-9.

23 Miller GJ, Beckles GLA, Alexis SD, Byam NTA, Price SGL. Serum lipoproteins and susceptibility of men of Indian descent to coronary heart disease. The St James survey, Trinidad. Lancet 1982;ii:200-3.

24 Beckles GLA, Miller GJ, Kirkwood BR, Alexis SD, Carson DC, Byam NTA High total and cardiovascular disease mortality in adults of Indian descent in Trinidad, unexplained by major coronary risk factors. Lancet 1986; 1298-301.

25 Zimmet P, Taylor R, Ram P, et al. Prevalence of diabetes and impaired glucose tolerance in the biracial (Melanesian and Indian) population of Fiji: a ruralurban comparison. Am f E pidemiol 1983;118:673-88.

26 Poon-King T, Henry MV, Rampersad F. Prevalence and natural history of diabetes in Trinidad. Lancet 1968; i: 155-60.

27 Omar MAK, Seedat MA, Dyer RB, Rajput MC, Motala AA, Joubert SM. The prevalence of diabetes mellitus in a large group of South African Indians. $S$ Afr Med F 1985;67:924-6.

28 Mather HM, Keen $\mathrm{H}$. The Southall diabetes survey: prevalence of known diabetes in Asians and Europeans. BMF 1985;291:1081-4

29 Stout RW, Vallance-Owen J. Insulin and atheroma. Lancet 1969;i:1078-80.

30 Stout RW. Insulin and atheroma - an update. Lancet 1987;i:1077-9.

31 Disler PB, Epstein L, Buchanan-Lee B, et al. Variations in mortality of the coloured, white and Asian population groups in the RSA, 1978-82. II. Cerebrovascular disease. S Afr Med f 1987;72:408-11.

32 Cruickshank JK, Beevers DG, Osbourne VL, Haynes RA, Corlett JCR, Selby S. Heart attack, stroke, diabetes, and hypertension in West Indians, Asians, and whites in Birmingham, England. BMF 1980;281:1108.

33 Faculty of Community Medicine of the Royal Colleges of Physicians of the United Kingdom. Coronary heart disease. I. Epidemiology. London: RCP 1988. (Guidelines for health promotion number 14. Produced by the Working Group on Coronary Heart Disease of the Committee on Health Promotion.

34 National Audit Office. National Health Service: coronary heart disease. Report by the comptroller and auditor general. London: HMSO, 1989.

\title{
Bupivacaine versus bupivacaine plus fentanyl for epidural analgesia: effect on maternal satisfaction
}

\author{
J D Murphy, K Henderson, M I Bowden, M Lewis, G M Cooper
}

\section{Department of}

Anaesthetics, Birmingham

Maternity Hospital,

Queen Elizabeth Medical

Centre, Birmingham

B15 2TG

J D Murphy, FCANAES, senior

registrar

K Henderson, MRCPI,

registrar

M I Bowden, FCANAES,

registrar

M Lewis, FCANAES,

consultant

G M Cooper, FCANAES, senior

lecturer

\section{Correspondence to: \\ Dr J D Murphy,}

Department of Anaesthetics,

Walsgrave Hospital,

Coventry CV2 2DX.

BMF 1991:302:564-7

\section{Abstract}

Objective-To compare a combination of epidural fentanyl and bupivacaine with bupivacaine alone for epidural analgesia in labour and to evaluate factors in addition to analgesia that may influence maternal satisfaction.

Design-A prospective randomised pilot study.

Setting-Birmingham Maternity Hospital.

Subjects -85 primiparous women who requested epidural analgesia in labour and their babies.

Interventions - Group 1 mothers were treated with bupivacaine conventionally, group 2 mothers with bupivacaine and fentanyl in a more complex way designed to provide satisfactory analgesia but with less troublesome side effects.

Main outcome measures-Overall maternal satisfaction, maternal perception of epidural analgesia and its side effects, and aspects of mothers' psychological states during labour, quantified using $100 \mathrm{~mm}$ visual linear analogue scales; the frequency of normal and operative deliveries; and measurements of neonatal wellbeing.

Results-Satisfaction was higher in group 2 mothers (median group difference $+3 \mathrm{~mm}, 95 \%$ confidence interval +1 to $+5, p=0.012)$ : this was associated with more normal deliveries (difference between proportions $0 \cdot 23,95 \%$ confidence interval +0.03 to +0.42 ); greater self control (median group difference $-7 \mathrm{~mm},-17$ to $-2, p=0.003)$; and reduced unpleasantness of motor blockade $(-10 \mathrm{~mm}$, -19 to $-5, \mathrm{p}<0.001)$, sensory blockade $(-5 \mathrm{~mm}$, -11 to $-2, p=0.002)$ and shivering $(-5 \mathrm{~mm}$, -18 to $0, p=0.046)$ at the expense of mild itching $(0 \mathrm{~mm}, 0$ to $0, p<0.001)$. Group 1 mothers found restricted movements more unpleasant $(-1 \mathrm{~mm}$, -11 to $0, p=0.006)$ and were more sleepy $(-4 \mathrm{~mm}$, -20 to $0, p=0.032$ ). The addition of fentanyl to bupivacaine reduced the requirement for local anaesthetic $(-33 \mathrm{mg},-55$ to $-15, \mathrm{p}<0.001)$ without compromising analgesia. No adverse effects in neonates were attributed to the use of fentanyl.

Conclusions-The already high maternal satisfaction from conventional epidural analgesia can be improved; epidural fentanyl may be combined with bupivacaine to reduce operative deliveries and confer other advantages that may increase maternal satisfaction. Further investigations should be performed to determine the exact mechanisms of these findings and, in particular, to develop a safe method of delivering such analgesia to women.

\section{Introduction}

The quality of epidural analgesia in labour has often been assessed by a simple statement that describes how well the mother was satisfied with the pain relief from 
her epidural. ${ }^{1-3}$ Overall maternal satisfaction may, however, be influenced by many factors other than pain relief.

When used alone epidural opioids have been unable to provide adequate analgesia throughout labour, ${ }^{+6}$ but the addition of the short acting, lipid soluble opioid fentanyl to bupivacaine has been more successful. ${ }^{3-10}$ It remains unclear, however, whether combinations of opioids and bupivacaine appreciably reduce the incidence of operative deliveries ${ }^{1112}$ and whether enhanced analgesia outweighs the inconvenience of using a controlled drug."

Our study was designed to evaluate some of the factors in addition to analgesia that may influence maternal satisfaction; at the same time we investigated the effects of a combination of epidural fentanyl and bupivacaine.

\section{Methods}

The study was approved by the research ethics committee. Healthy, English speaking, primiparous women at term with a singleton fetus with cephalic presentation were invited to participate if they requested epidural analgesia in labour. Mothers were not recruited if they had previously experienced or had any contraindication to epidural analgesia or if they had an abnormal fetus or a degree of pre-eclampsia that required treatment.

After setting up an intravenous infusion of Hartmann's solution an epidural catheter was inserted into a lumbar interspace using a 16 gauge Tuohy needle. Initially, $4 \mathrm{ml}$ of $0 \cdot 25 \%$ bupivacaine was given epidurally with the mother lying on her left side. After five minutes this dose was repeated with the mother lying on her right side unless her pain had disappeared. If the mother was still in severe pain the anaesthetist continued to top up with the same dose at minimum intervals of five minutes.

The study was explained to each mother when she was reasonably comfortable. Verbal consent was thus obtained when she was less distracted by her pain. The mother was then allocated to one of the two treatment groups ( 1 or 2 ) by opening a sealed envelope from a random series. Written consent was obtained when she had been made as comfortable as possible.

Mothers in group 1 were topped up by either a midwife or an anaesthetist with $5 \mathrm{ml}$ of $0.25 \%$ bupivacaine; this was repeated after five minutes unless the mother's pain had disappeared. These top ups could be given at hourly intervals by the midwife, but the anaesthetist was called if analgesia was needed sooner. Mothers were allowed to sit or lie on their sides, although they were advised to sit up whenever top ups were given to provide perineal analgesia. Mothers in group 2 received either $4 \mathrm{ml}$ of $0.25 \%$ bupivacaine for pain restricted to the abdomen, or 10 $\mathrm{ml}$ of $0 \cdot 1 \%$ bupivacaine containing $50 \mu \mathrm{g}$ fentanyl if they had perineal pain. ${ }^{3}$ Midwives were permitted to give these bupivacaine top ups at 10 minute intervals, but only anaesthetists gave top ups with fentanyl, which could be repeated after 20 minutes. A maximum amount of fentanyl was permitted; this was $200 \mu \mathrm{g}$ in the first six hours plus an extra $50 \mu \mathrm{g}$ for each subsequent two hours. Fentanyl was omitted if either its maximum dose had been reached or delivery was considered imminent. Mothers were asked to lie on their sides until delivery.

Both groups received intermittent top ups, on demand, throughout both stages of labour. ${ }^{13}$ Inadequate analgesia, resulting from either technique, was treated by the anaesthetist, who gave extra boluses of $4 \mathrm{ml}$ of $0.25 \%$ bupivacaine at minimum intervals of five minutes. After three such top ups the anaesthetist progressed to $4 \mathrm{ml}$ boluses of $0.5 \%$ bupivacaine, provided that he or she was satisfied with the position of the epidural catheter.

Any comfortable position that eliminated caval occlusion was allowed for normal deliveries in both groups. Whenever an episiotomy was required the midwife tested the perineum for sensation and infiltrated lignocaine if necessary. If an operative delivery was required the anaesthetist ensured that appropriate anaesthesia was provided and positioned the patient with a $15^{\circ}$ left lateral tilt. Obstetricians were not told which treatment each mother had received. The management of labour and delivery was similar for all mothers according to the hospital's standard regimens.

The anaesthetist attended deliveries and collected blood samples from the umbilical vein and artery; the samples were analysed to determine $\mathrm{pH}$, carbon dioxide tension, oxygen tension, and base excess. Apgar scores at 1 and 5 minutes were estimated by either the attendant midwife or a paediatrician. Intramuscular naloxone was given to neonates who were judged to have ventilatory depression if their mothers had been treated with any opioid during labour. The anaesthetist assessed each mother individually and decided when she could leave the delivery suite ${ }^{14}$ if there were no obstetric problems.

On the day after delivery all mothers were interviewed by the same consultant anaesthetist (ML), who was unaware of the technique used; mothers quantified their perception of epidural analgesia and its side effects and aspects of their psychological state during labour using separate $100 \mathrm{~mm}$ visual linear analogue scales. Whenever a mother denied experiencing any particular side effect she was awarded a score of zero for that problem and did not complete the relevant analogue scale.

Statistical analyses were performed using the MannWhitney $\mathrm{U}$ test, and group differences are given with $95 \%$ confidence intervals.

\section{Results}

Eighty five mothers were included in the study during a two month period; 42 were allocated to group 1 and 43 to group 2 . The two groups were similar with respect to age, weight, dilatation of the cervix at the start of epidural analgesia, lumbar space used, analgesia beforehand, and frequency of inductions with oxytocin (table I). Women in group 1 had their labours augmented with oxytocin more often than those in group 2, but the difference was not significant (table I). Epidural analgesia was managed by the first three authors.

Forty mothers (93\%) in group 2 experienced perineal pain and were therefore treated with bupivacaine and fentanyl. The greatest amount of fentanyl received by any woman was $400 \mu \mathrm{g}$ over 16

TABLE I-Clinical data of 85 women. Results are numbers unless otherwise stated

\begin{tabular}{lcc}
\hline & $\begin{array}{c}\text { Group 1 } \\
(\mathbf{n}=42)\end{array}$ & $\begin{array}{c}\text { Group 2 } \\
(\mathbf{n}=43)\end{array}$ \\
\hline Mean (SD) age (years) & $26(5)$ & $26(5)$ \\
Mean (SD) weight (kg) & $75(10)$ & $77(13)$ \\
Mean (SD) dilatation of cervix at start of & & \\
$\quad$ epidural (cm) & $4 \cdot 9(1 \cdot 8)$ & $4 \cdot 7(2 \cdot 0)$ \\
Lumbar space used: & 36 & 39 \\
$\quad$ L.2-3 & 4 & 4 \\
L.1-2 & 2 & \\
L.3-4 & 17 & 20 \\
Analgesia before epidural: & 2 & 2 \\
Nitrous oxide and oxygen & 5 & 7 \\
Pethidine & 18 & 14 \\
$\quad$ Nitrous oxide and oxygen and pethidine & & \\
$\quad$ None & 7 & 7 \\
Use of oxytocin: & 23 & 15 \\
$\quad$ Induction of labour & 12 & 21 \\
$\quad$ Augmentation of labour & & \\
$\quad$ Not used & & \\
\hline
\end{tabular}


hours. Obvious ventilatory depression was not seen in any mother. Several mothers in each group required additional top ups of $0 \cdot 25 \%$ bupivacaine for inadequate

TABLE II-Analgesic requirements of women. Figures are median values for each group

\begin{tabular}{|c|c|c|c|}
\hline & $\begin{array}{l}\text { Group } 1 \\
(n=42)\end{array}$ & $\begin{array}{c}\text { Group 2 } \\
(n=43)\end{array}$ & $\begin{array}{c}\text { Median difference } \\
\text { between groups } \\
(95 \% \text { confidence interval })\end{array}$ \\
\hline $\begin{array}{l}\text { Time from epidural to delivery } \\
(\min )\end{array}$ & 368 & 329 & $-47(-144$ to +33$)$ \\
\hline Total bupivacaine used (mg) & 95 & 60 & $-33(-55$ to -15$)$ \\
\hline Total fentanyl used $(\mu \mathrm{g})^{\star}$ & 0 & 150 & $150(+100$ to +200$)$ \\
\hline
\end{tabular}

${ }^{\star}$ Excluding any top up given for operative delivery.

TABLE III-Mode of delivery. Figures are numbers of mothers

\begin{tabular}{|c|c|c|}
\hline Delivery & Group 1 & Group 2 \\
\hline Normal & $10^{\star}$ & $20^{\star}$ \\
\hline Operative: & 32 & 23 \\
\hline Simple forceps & 16 & 12 \\
\hline Rotational forceps & 5 & 1 \\
\hline Ventouse extractions & 1 & 3 \\
\hline Caesarean section & 10 & 7 \\
\hline
\end{tabular}

^Difference between the proportions of each group having normal deliveries $=0 \cdot 23(95 \%$ confidence interval $+0 \cdot 03$ to $+0 \cdot 42)$.

TABLE IV-Neonatal outcome of babies delivered vaginally. Figures are mean $(S D)$ or as indicated

\begin{tabular}{|c|c|c|}
\hline & $\begin{array}{c}\text { Group 1 } \\
(\mathrm{n}=32)\end{array}$ & $\begin{array}{c}\text { Group 2 } \\
(\mathrm{n}=36)\end{array}$ \\
\hline Birth weight $(\mathrm{g})$ & $3250(470)$ & $3420(450)$ \\
\hline \multicolumn{3}{|l|}{ No with Apgar scores below 7: } \\
\hline After 1 minute & 3 & 1 \\
\hline After 5 minutes & 0 & 0 \\
\hline \multicolumn{3}{|l|}{ Umbilical vein values: } \\
\hline No of samples & 30 & 33 \\
\hline $\mathrm{pH}$ & $7 \cdot 33(0.05)$ & $7.33(0.05)$ \\
\hline $\mathrm{PCO}_{2}(\mathrm{kPa})$ & $5 \cdot 5(0 \cdot 7)$ & $5 \cdot 6(0.8)$ \\
\hline $\mathrm{Po}_{2}(\mathrm{kPa})$ & $3 \cdot 5(0 \cdot 6)$ & $3.6(0.7)$ \\
\hline Base excess $(\mathrm{mmol} / \mathrm{l})$ & $-3 \cdot 4(2 \cdot 3)$ & $-3 \cdot 4(2 \cdot 0)$ \\
\hline \multicolumn{3}{|l|}{ Umbilical artery values: } \\
\hline No of samples & 24 & 32 \\
\hline $\mathrm{pH}$ & $7 \cdot 25(0.06)$ & $7 \cdot 25(0.07)$ \\
\hline $\mathrm{PCO}_{2}(\mathrm{kPa})$ & $7 \cdot 5(1 \cdot 1)$ & $7 \cdot 6(1.3)$ \\
\hline $\mathrm{PO}_{2}(\mathrm{kPa})$ & $2.3(0.9)$ & $2 \cdot 2(0 \cdot 7)$ \\
\hline Base excess $(\mathrm{mmol} / \mathrm{l})$ & $-3 \cdot 6(2 \cdot 8)$ & $-3 \cdot 6(2 \cdot 4)$ \\
\hline
\end{tabular}

TABLE V-Maternal satisfaction with analgesia. Group scores expressed as 25 th-75th centiles

\begin{tabular}{|c|c|c|c|c|}
\hline & $\begin{array}{l}\text { Group 1 } \\
(n=42)\end{array}$ & $\begin{array}{c}\text { Group 2 } \\
(\mathrm{n}=43)\end{array}$ & $\begin{array}{l}\text { p Value (from } \\
\text { Mann-Whitney } \\
\text { U test) }\end{array}$ & $\begin{array}{c}\text { Median difference } \\
\text { between groups } \\
\text { (95\% confidence interval) }\end{array}$ \\
\hline \multicolumn{5}{|l|}{ Sensation: } \\
\hline Pain before epidural (mm) & $65-90$ & $66-95$ & $0 \cdot 208$ & $5(-3$ to +11$)$ \\
\hline Pain after epidural (mm) & $3-15$ & $2-18$ & $0 \cdot 49$ & $-1(-4$ to +2$)$ \\
\hline $\begin{array}{l}\text { Pain at delivery (normals only) }(\mathrm{mm}) \\
\text { (no pain }=0, \text { worst pain }=100)\end{array}$ & $10-50$ & $2-50$ & $0 \cdot 174$ & $-7(-26$ to +15$)$ \\
\hline $\begin{array}{l}\text { Analgesia score }(\mathrm{mm}) \\
\text { (pain before minus pain after epidural) }\end{array}$ & $51-84$ & $48-88$ & $0 \cdot 49$ & $4(-8$ to +14$)$ \\
\hline $\begin{array}{l}\text { Urge to push }(\mathrm{mm}) \\
\text { (no urge }=0, \text { overwhelming urge }=100)\end{array}$ & $4-85$ & $3-59$ & $0 \cdot 674$ & $-1(-16$ to +1$)$ \\
\hline \multicolumn{5}{|l|}{ Side effects: } \\
\hline Weakness in legs $(\mathrm{mm})$ & $5-46$ & $0-9$ & $<0.001$ & $-10(-19$ to -5$)$ \\
\hline Numbness $(\mathrm{mm})$ & $3-46$ & $0-14$ & 0.002 & $-5(-11$ to -2$)$ \\
\hline Difficulty in micturition $(\mathrm{mm})$ & $1-10$ & $0-7$ & 0.064 & $-1(-4$ to 0$)$ \\
\hline Itching $(\mathrm{mm})$ & $0-0$ & $0-5$ & $<0.001$ & \\
\hline Nausea $(\mathrm{mm})$ & $0-29$ & $0-0$ & 0.057 & \\
\hline Restricted movements $(\mathrm{mm})$ & $0-41$ & $0-5$ & $0 \cdot 006$ & $-1(-11$ to 0$)$ \\
\hline $\begin{array}{l}\text { Shivering }(\mathrm{mm}) \\
(\text { no trouble }=0, \text { extremely unpleasant }=100)\end{array}$ & $0-56$ & $0-29$ & $0 \cdot 046$ & $-5(-18$ to 0$)$ \\
\hline \multicolumn{5}{|l|}{$\begin{array}{l}\text { Psychological state: } \\
\end{array}$} \\
\hline $\begin{array}{l}\text { Sedation after epidural }(\mathrm{mm}) \\
(\text { wide awake }=0, \text { extremely sleepy }=100)\end{array}$ & $5-75$ & $1-47$ & 0.032 & $-4(-20$ to 0$)$ \\
\hline $\begin{array}{l}\text { Mood after epidural }(\mathrm{mm}) \\
\text { (miserable }=0, \text { extremely happy }=100 \text { ) }\end{array}$ & $45-92$ & $62-96$ & $0 \cdot 101$ & $7(-1$ to +19$)$ \\
\hline Self control before epidural (mm) & $46-93$ & $27-91$ & 0.465 & $-3(-14$ to +7$)$ \\
\hline $\begin{array}{l}\text { Self control after epidural }(\mathrm{mm}) \\
(\text { completely }=0, \text { no control }=100)\end{array}$ & $6-47$ & $3-25$ & 0.003 & $-7(-17$ to -2$)$ \\
\hline $\begin{array}{l}\text { Expectations }(\mathrm{mm}) \\
(\text { nothing like expected }=0 \\
\quad \text { exactly as expected }=100\end{array}$ & $12-86$ & 3-78 & $0 \cdot 222$ & $-6(-19$ to +3$)$ \\
\hline $\begin{array}{l}\text { Overall satisfaction }(\mathrm{mm}) \\
\quad(\text { none }=0, \text { completely }=100)\end{array}$ & $85-96$ & $92-99$ & $0 \cdot 012$ & $3(+1$ to +5$)$ \\
\hline
\end{tabular}

analgesia, but only one mother (in group 1) needed top ups of $0.5 \%$ bupivacaine. Six mothers in group 1 received fentanyl as part of a top up in preparation for an operative delivery. ${ }^{15}$ Table II shows that mothers in group 2 received less bupivacaine than those in group 1 over a similar time.

Table III shows that mothers in group 2 had more normal deliveries than those in group 1 . The frequency of each type of operative delivery is shown.

Table IV shows measurements of neonatal wellbeing (Apgar scores and fetal biochemistry) for babies who were delivered vaginally. There were no appreciable differences between the groups. Similar results from babies who were delivered by caesarean section are not reported as the samples were small and not standardised for anaesthetic technique; either general or epidural anaesthesia was used. Two neonates were treated with naloxone after ventilatory depression was diagnosed (one in each group).

One mother from group 1 received $100 \mu \mathrm{g}$ fentanyl 38 minutes before delivery, as part of a top up in preparation for an operation. She subsequently had a non-rotational forceps delivery, which proved difficult and traumatic; her baby was born with a bruised and cut face, Apgar scores of 5 and 7 at 1 and 5 minutes respectively, and normal biochemical values. The baby improved after being given intramuscular naloxone and oxygen simultaneously using intermittent positive pressure ventilation but required transfer to the neonatal unit for treatment of his facial injury.

One mother from group 2 received $150 \mu \mathrm{g}$ fentanyl during her labour; the last fentanyl top up was 116 minutes before a normal delivery, which was complicated by mild shoulder dystocia. The mother had also received $200 \mathrm{mg}$ pethidine before her epidural; the last dose was five hours before delivery. The baby had Apgar scores of 8 and 8 at 1 and 5 minutes respectively and normal biochemical values. Naloxone was given to this baby by the midwife because of the recent use of opioids in the mother. It was not clear that the baby had ventilatory depression, and even after naloxone he did not recover immediately but was troubled by tachypnoea and grunting for another two hours after birth.

Factors that may have contributed to overall maternal satisfaction are listed under sensation, side effects, and psychological state (table V). There were no appreciable differences between the groups in scores for pain before and after the epidural or during normal deliveries. Calculated analgesia scores (pain score before epidural minus pain score after epidural) and the urge to push during the second stage of labour were also similar in both groups. The unpleasantness of leg weakness, numbness, restricted movements, and shivering were all significantly less in group 2 mothers, although $14(33 \%)$ experienced mildly troublesome itching, their median score for itching being $14 \mathrm{~mm}$. Group 2 mothers were also more awake, and they had greater self control with epidural analgesia. Finally, although overall satisfaction was high in group 1 mothers, it was significantly higher in group 2 mothers.

\section{Discussion}

Our most striking finding, which has not been reported previously, is that women who received a combination of bupivacaine and fentanyl were roughly twice as likely to have a normal delivery (table III). Moreover, only one mother who received the combination required a rotational forceps delivery, compared with five who received bupivacaine alone. The confidential inquiry into maternal deaths shows mortality to be greater after operative deliveries. ${ }^{16}$ Although maternal morbidity is more difficult to measure, the average duration of stay in hospital is 
longer after operative deliveries. The recognised association between the use of obstetric forceps and serious neonatal morbidity and mortality has recently been reiterated. Clearly, the frequency of operative deliveries should be reduced whenever possible, and enhancing bupivacaine analgesia by fentanyl may help to do this.

Using fentanyl with bupivacaine significantly reduced the requirement for bupivacaine without compromising analgesia (tables II and V). We suspect that this reduced dose of local anaesthetic was the single most important factor contributing to the benefits we have shown. Clearly the lower dose of bupivacaine was associated with many of the recognised side effects of neural blockade being less unpleasant for mothers. Although pain relief was similar in both groups, overal satisfaction was significantly higher in mothers in group 2 (table V). This higher satisfaction can reasonably be accounted for by other benefits that these mothers experienced, although they may also have had greater contact with their anaesthetist. It was ethically difficult to avoid this potential bias as neither anaesthetists nor midwives would have been available to give al top ups without more frequent delays before mothers received analgesia. Further investigations would be required to determine the exact mechanisms that may have resulted in the differences between the two groups. As in other studies itching occurred with epidural fentanyl, but this was not a troublesome side effect. ${ }^{11}$

Interestingly, mothers in group 1 felt more restricted than group 2 mothers. Presumably the group 1 mothers felt restricted because of their leg weakness whereas those in group 2, although having the power to move, had been asked to stay lying on their sides. Group 2 mothers were positioned in this way in the hope of limiting caudal spread of local anaesthetic solution, thus reducing sacral neural blockade, which may be associated with instrumental deliveries ${ }^{18}$; we expected to provide satisfactory analgesia without the influence of gravity because the site of action of fentanyl is in the spinal cord itself, rather than the sacral nerves. ${ }^{3}$ Also, interestingly, group 1 mothers felt more sleepy. Although sedation is a recognised side effect of local anaesthetics, ${ }^{19}$ it is also possible that group 2 mothers were able to rest more, owing to their position, or that group 1 mothers were simply more tired before labour. In the mothers we studied fentany probably did not have a more troublesome sedative effect than bupivacaine alone.

No adverse effects were attributed to fentanyl in the neonates of mothers who were treated with this drug (table IV). Although one neonate in each group was treated with naloxone, neither infant appeared to be suffering from purely opioid induced ventilatory depression, and in both cases the indication for naloxone can be questioned. Neurobehavioural tests ${ }^{20}$ were not used in our pilot study, but their use in future studies may provide a more sensitive indicator of residual effects of both bupivacaine and fentanyl in neonates.

Our use of fentanyl was restricted within a total dose that had previously been shown to be safe ${ }^{9}$ and for treating perineal pain, which is a recognised indication for epidural fentanyl. ${ }^{3}$ Possibly, if the safety of a greater total dose of epidural fentanyl can be assured then the benefits that we have found may be increased. Fentanyl has been used in obstetric epidural analgesia without serious complications except for a case of profound ventilatory depression that was reported in a patient undergoing caesarean section. ${ }^{14}$ The epidural block in this case was unusually high (it extended to $\mathrm{C4}$ ), and this high block was probably a major contributing factor. Nevertheless, the case reinforces the need for constant vigilance with any technique of epidural analgesia in obstetrics.

The major disadvantage that we found with the combination technique was that the required frequency of top ups resulted in a heavy workload for the anaesthetist. A similar problem could be expected if midwives are instructed and permitted to give such top ups. We fear that this successful technique will be considered too onerous and therefore impracticable in hospitals where there is concern over the workload of junior doctors and where chronic midwifery staff shortages exist. Unless these problems can be overcome, therefore, there is a real need to search for an alternative system to deliver similar techniques of analgesia. Epidural infusions of local anaesthetics have not been shown to reduce the frequency of operative deliveries, although they may reduce the need for frequent top ups, ${ }^{221}$ and the addition of fentanyl has decreased the requirement for local anaesthetic. ${ }^{910}$ Interindividual variation in dosage requirements makes it difficult with infusions to provide satisfactory analgesia for all women without a relative overdose in some. Early experiences with patient controlled epidural analgesia have been encouraging, ${ }^{22-24}$ and this method could provide the ultimate solution if an optimum regimen can be determined and its safety and efficacy adequately shown.

We thank the midwives in the delivery suite of Birmingham Maternity Hospital for their help.

1 Crawford JS. Lumbar epidural block in labour: a clinical analysis. Br $\mathcal{A}$ Anaesth 1972;44:66-74

Lamont RF, Pinney D, Rodgers P, Bryant TN. Continuous versus intermitten epidural analgesia. Anaesthesia 1989;44:893-6.

3 Reynolds F, O'Sullivan G. Epidural fentanyl and perineal pain in labour. Anaesthesia 1989;44:341-4.

4 Crawford JS. Experiences with epidural morphine in obstetrics. Anaesthesia $1981 ; 36: 207-9$

5 Husemever RP', O'Connor MC, Davenport HT. Failure of epidural morphine to relieve pain in labour. Anaesthesia 1980;35:161-3.

6 Carrie LES, O'Sullivan GM, Seegobin R. Epidural fentanyl in labour. Anaesthesia 1981;36:965-9.

7 Justins DM, Francis D, Houlton PG, Reynolds F A controlled trial of extradural fentanyl in labour. Brf Anaesth 1982;54:409-14

8 Vella L.M, Willatts DG, Knott C, Linton DJ, Justins DM, Reynolds F Epidural fentanyl in labour: an evaluation of the systemic contribution to analgesia Anaesthesia 1985;40:741-7.

9 Jones G, Paul DL, Elton RA, McClure JH. Comparison of bupivacaine and bupivacaine with fentanyl in continuous extradural analgesia during labour. BrF Anaesth 1989;63:254-9.

10 Chesnut DH, Owen CL, Bates JN, Ostman LG, Choi WW, Geiger MW Continuous infusion epidural analgesia during labor: a randomised, double-blind comparison of $0 \cdot 0625 \%$ bupivacaine $/ 0 \cdot 0002 \%$ fentanyl versu 0.125\% bupivacaine. Anesthesiology 1988;68:754-9.

11 Revnolds F. Extradural opioids in labour. Br 7 Anaesth 1989;63:251-3.

12 Herman NL. Hussain FL, Knape KG, Downing JW. Extradural opioids in labour. Br f Anaesth 1990;64:528-9.

13 Phillips KC, Thomas TA. Second stage of labour with or without extradural analgesia. Anaesthesia 1983;38:972-6.

14 Brockway MS, Noble DW, Sharwood-Smith GH, McClure JH. Profound respiratory depression after extradural fentanyl. Br f Anaesth 1990;64: 243-5

15 King MJ, Bowden MI, Cooper GM. Epidural fentanyl and $0.5 \%$ bupivacaine for elective caesarean section. Anaesthesia 1990;45:285-8.

16 Department of Health. Report on confidential enquiries into maternal deaths in England and W'ales. London: HMSO, 1989.

17 Ennis M, Vincent CA. Obstetric accidents: a review of 64 cases. BM 1990;300:1365-7.

18 Doughty A. Selective epidural analgesia and the forceps rate. Br $\mathcal{Y}$ Anaesth $1969 ; 41: 1058-62$

19 De Jong RH. Physiology and pharmacology of local anaesthesia. Illinois: Thomas, 1970

20 Brazelton TB. Neonatal behavioural assessment scale. London: Blackwell Scientific Publications, 1984

21 Bogod DG, Rosen M, Rees GAD. Extradural infusion of $0 \cdot 125 \%$ bupivacaine at $10 \mathrm{mls} \mathrm{h}$ ' $t o$ women during labour. Br $\mathcal{F}$ Anaesth 1987;59:325-30.

22 Gambling DR, Yu P, Cole C, McMorland GH, Palmer N. A comparative study of patient controlled epidural analgesia (PCEA) and continuous study of patient controlled epidural analgesia (PCEA) and continuous
infusion epidural analgesia (CIEA) during labour. Can $f$ Anaesth infusion epidurat

23 Gambling DR, McMorland GH, Yu P, Laszlo C. Comparison of patient controlled epidural analgesia and conventional intermittent "top-up" injections during labor. Anesth Analg 1990;70:256-61

24 Lysak SZ, Eisenach JC, Dobson CE. Patient-controlled epidural analgesia during labor: a comparison of three solutions with a continuous infusion control. Anesthesiology 1990;72:44-9.

(Accepted 7 fanuary 1991) 